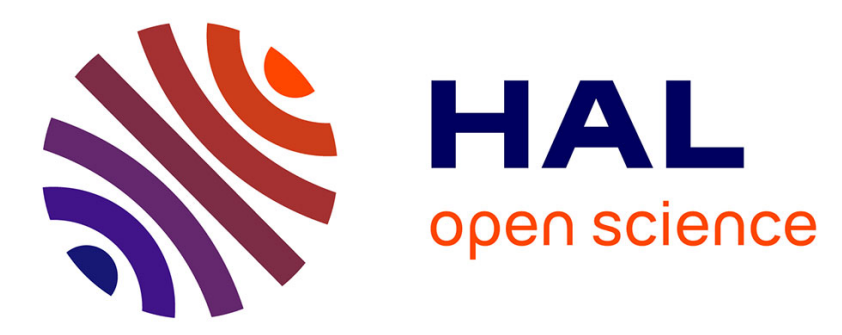

\title{
Anodic Deposition of Enantiopure Hexahelicene Layers
} Jan Vacek, Jan Hrbac, Tomas Strasak, Vladimir Cirkva, Jan Sykora, Ladislav Fekete, Jan Pokorny, Jiri Bulir, Magdalena Hromadova, Jeanne Crassous, et al.

\section{- To cite this version:}

Jan Vacek, Jan Hrbac, Tomas Strasak, Vladimir Cirkva, Jan Sykora, et al.. Anodic Deposition of Enantiopure Hexahelicene Layers. ChemElectroChem, 2018, 5 (15), pp.2080-2088. 10.1002/celc.201800565 . hal-01874560

\section{HAL Id: hal-01874560 https://hal-univ-rennes1.archives-ouvertes.fr/hal-01874560}

Submitted on 20 Sep 2018

HAL is a multi-disciplinary open access archive for the deposit and dissemination of scientific research documents, whether they are published or not. The documents may come from teaching and research institutions in France or abroad, or from public or private research centers.
L'archive ouverte pluridisciplinaire HAL, est destinée au dépôt et à la diffusion de documents scientifiques de niveau recherche, publiés ou non, émanant des établissements d'enseignement et de recherche français ou étrangers, des laboratoires publics ou privés. 


\title{
Anodic Deposition of Enantiopure Hexahelicene Layers
}

\author{
Jan Vacek, ${ }^{\left[\mathrm{a},{ }^{*}\right]}$ Jan Hrbáč,${ }^{[\mathrm{b}, * *]}$ Tomáš Strašák, ${ }^{[\mathrm{c}]}$ Vladimír Církva, ${ }^{[\mathrm{c}]}$ Jan Sýkora, ${ }^{[\mathrm{c}]}$ \\ Ladislav Fekete, ${ }^{[\mathrm{d}]}$ Jan Pokorný, ${ }^{[\mathrm{d}]}$ Jiří Bulî́r, ${ }^{[\mathrm{d}]}$ Magdalena Hromadová, ${ }^{[\mathrm{e}]}$ \\ Jeanne Crassous, ${ }^{[\mathrm{f}]}$ and Jan Storch, ${ }^{[\mathrm{c}, * * *]}$
}

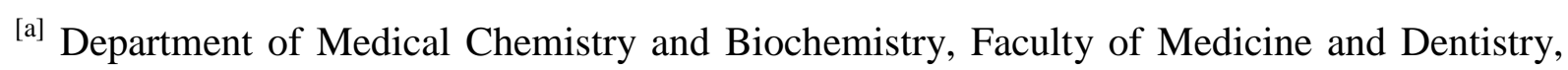
Palacký University, Hněvotínská 3, 77515 Olomouc, Czech Republic

${ }^{[b]}$ Institute of Chemistry, Masaryk University, Kamenice 5, 72500 Brno, Czech Republic

${ }^{[c]}$ Institute of Chemical Process Fundamentals of the Czech Academy of Sciences, Rozvojová 135, 16502 Prague 6, Czech Republic

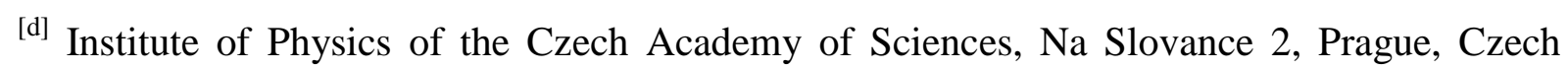
Republic

[e] J. Heyrovský Institute of Physical Chemistry of the Czech Academy of Sciences, Dolejškova 3, 18223 Prague, Czech Republic

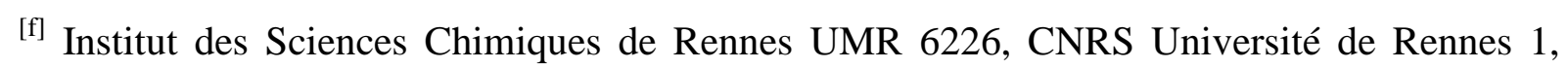
Campus de Beaulieu, Rennes Cedex, France

Corresponding authors: *J. Vacek (electrochemistry and spectroscopy) jan.vacek@upol.cz; *** Hrbac (electrosynthetic approach) jan.hrbac@upol.cz; ${ }^{* * *}$ J. Storch (helicene synthesis and computational chemistry) storchj@icpf.cas.cz. 


\begin{abstract}
Helicenes are polyaromatic compounds with chiral properties useful for many applications in optoelectronics, separation processes, chiral recognition and catalysis. Here we focused on the electrochemistry of carbo $[n]$ helicenes $(n=5,6,7)$. The cyclic voltammograms of racemic mixtures of target compounds in acetonitrile/0.1 $\mathrm{M}$ tetrabutylammonium perchlorate at a glassy carbon electrode reveal the diffusion-controlled reactions in both anodic and cathodic potential regions. Electrochemical behaviors are different for individual helicenes, [7]helicene undergoes redox transformation easily in comparison to the other investigated compounds, which is in agreement with DFT (density functional theory) calculations. Generally, the multicomponent anodic process of helicenes is observable at potentials from +1.5 to $+2.5 \mathrm{~V}$, leading to the formation of deposited structures (layers) on the electrode surface. The helicenes were electrodeposited onto transparent indium tin oxide (ITO) electrodes and characterized by atomic force microscopy, UV/Vis, Raman spectroscopy and ellipsometry. Finally, the anodic deposition of $P$ and $M$ enantiomers of [6]helicene was performed using ITO substrates, resulting in the formation of enantiopure layers of nanometer thicknesses, as confirmed by circular dichroism spectroscopy. The discovered electrosynthetic procedure opens up a new possibility for the immobilization of chiral helicene layers onto solid supports.
\end{abstract}

Keywords: helicene, redox behavior, electrosynthesis, voltammetry, electronic and spectral properties 


\section{Graphical Abstract:}

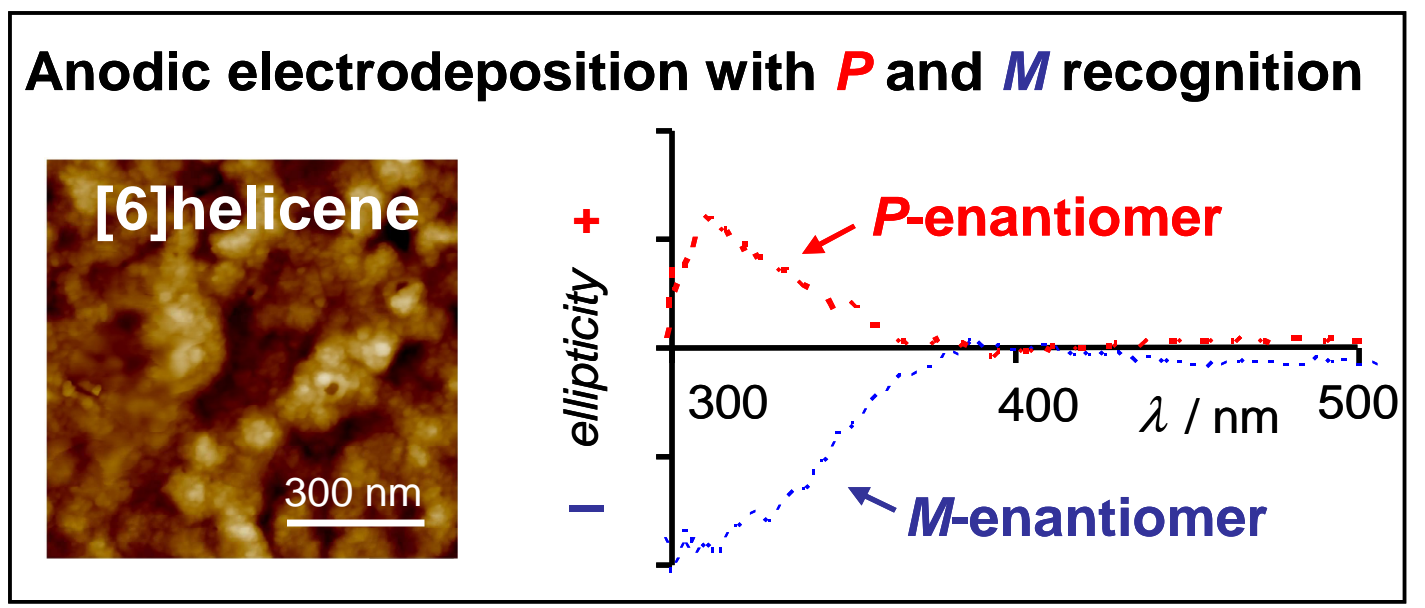

The electrochemical behavior, electronic properties and spectral characterization of carbo[ $n]$ helicenes $(n=5,6,7)$ are reported. The comparative study focused on the anodic electrodeposition of helicene layers, which are chiral for hexahelicene.

\section{Introduction}

Helicenes are inherently chiral polyaromatic compounds comprised of all-ortho fused aromatic rings with a delocalized system of $\pi$-electrons. They have a $C_{2}$ axis of symmetry, and are chiral regardless of the absence of a stereogenic centre in the molecule. Despite the fact that helicenes have been known for decades, their promising properties have attracted considerable attention and stimulated multidisciplinary research toward a broad spectrum of applications, as was recently reviewed in ${ }^{[1-4]}$. Helicenes have already proved to be useful in the field of asymmetric catalysis ${ }^{[1-3]}$, molecular recognition ${ }^{[5-7]}$, supramolecular chemistry ${ }^{[8-}$ ${ }^{11]}$, and the development of new materials ${ }^{[12,13]}$, including soft (gelation) materials and selfassembled structures and electronic devices ${ }^{[14-17]}$. Since pure helicenes (carbohelicenes) are commercially available, their derivatization studies have emerged ${ }^{[4]}$. In addition to the conductive properties of helicenes, helicenes have an abnormally high values of specific rotation as well as strong circular dichroism ${ }^{[18]}$. Helicenes and their derivatives are thus 
promising candidates for the development of devices using circularly polarized luminescence $[19,20]$. An application field for helicenes can be found in the development of organic molecular optoelectronic devices, such as nonlinear optics (NLO) components, circularly polarized light sources and detectors, OLED - organic light emitting diodes, OFET - organic field effect transistors and electrochemical sensors ${ }^{[1-3]}$.

A crucial aspect of the above applications is the immobilization of helicenes onto the solid substrates prior to direct use or implementation into chiroptical or electrical devices. There are two possibilities for performing the immobilization step. The relatively good solubility of helicene monomers, when compared to the solubility of many other polyaromatic molecules, enables the preparation of immobilized layers by simple techniques, such as spincoating and drop-casting, large-scale or advanced ink-jet printing ${ }^{[21,22]}$. Another option for preparing helicene layers, molecular junctions or devices is based on more complex (polymeric) structures bearing helicene units as the chiral active element. A well-known example is helicene-derived conjugated polymers. The original finding is based on the nickelsalophen-hexahelicene structure ${ }^{[23]}$, which was later extended for the preparation of conjugated helical acetylene-bridged polymers ${ }^{[24]}$, helical polyacetylenes bearing helicene pendants ${ }^{[25]}$ and benzo[5]helicene-based polymers. These polymers have already found an application in chiral recognition and in the separation and construction of new chemosensors. In addition, an electrosynthetic approach was recently utilized for the preparation of overoxidized deposits ${ }^{[13]}$ and conductive thin layers ${ }^{[26]}$ of [7]helicene.

It is obvious that there will be an extensive utilization of helicenes in various areas of materials science, especially in optoelectronics. However, to the best of our knowledge no studies have been performed investigating the basic electrochemical behavior of carbohelicenes, only theoretical papers have been published ${ }^{[27]}$. The purpose of this work is to provide an electrochemical study of $[n]$ helicenes. Specifically, racemic penta-, hexa- and 
heptahelicenes and P/M enantiopure forms of hexahelicene were investigated electrochemically, and the results were supported by computational chemistry tools. Last but not least, the electrosynthetic procedure reported here opens up a new possibility for the immobilization of optically pure helicenes onto solid supports.

\section{Experimental part}

\section{Chemicals}

Racemic penta- ${ }^{[28]}$, hexa- ${ }^{[29]}$, and hepta- ${ }^{[30]}$ helicenes were prepared according to the published procedures. The resolution of hexahelicene into single enantiomers ( $\mathrm{M}$ and $\mathrm{P}$ ) was performed using the HPLC separation technique (for conditions, see ${ }^{[31]}$ ). Tetrabutylammonium perchlorate - TBAP (Fluka), tetrabutylammonium hexafluorophosphate - TBAPF $_{6}$ (Sigma-Aldrich), acetonitrile - ACN, anhydrous, >99.8\% (Sigma-Aldrich), ferrocene, potassium ferricyanide (Lachema), and hexaammineruthenium(III) chloride (Sigma-Aldrich) were used. The electrolyte was dried before use at elevated temperature, and ACN was treated with a $3 \AA$ activated molecular sieve (Lachema, Brno, Czech Republic), which decreased the water content to $<25 \mathrm{ppm}$ based on Karl Fischer titration. The sample preparation and analyses were performed under ambient (air) conditions unless stated otherwise.

\section{Cyclic voltammetry}

Electrochemical experiments were conducted using a Nanoampere electrochemical workstation (L-Chem, CZ). A CHI MF-2012 glassy carbon electrode (disc, approx. 7 mm²), and indium tin oxide (ITO)-coated glass slides with a surface resistivity of $8-12 \Omega /$ sq, (Sigma Aldrich) were used as the working electrodes, $\mathrm{Ag} / \mathrm{AgCl} / 3 \mathrm{M} \mathrm{KCl}$ (RE-5B, Bioanalytical Systems, Inc., USA) and a platinum wire served as the reference and auxiliary electrodes, 
respectively. Ferrocene was used as an internal standard, giving an $E_{1 / 2}$ of $438 \mathrm{mV}$, which is in agreement with the literature data $\left(e . g .430 \mathrm{mV}\right.$ in $\left.{ }^{[32]}\right)$. Based on independent observations $(n=12)$, the relative standard deviation for potentials of onsets or peaks was $\pm 6 \mathrm{mV}$. All experiments were done from the solution of helicenes in ACN/0.1 M TBAP at $20{ }^{\circ} \mathrm{C}$. The compactness of helicene layers was evaluated using $\mathrm{Fe} / \mathrm{Ru}$ markers according to previously described approaches ${ }^{[33]}$. The post-acquisition processing of electrochemical data was performed with the freeware package eL-Chem viewer ver. $2^{[34]}$.

\section{Bulk electrolysis}

Solutions of $1 \mathrm{mM}$ helicenes in $\mathrm{ACN} / 0.1 \mathrm{M} \mathrm{TBAPF}_{6}$ were electrolyzed at $E=+2.5 \mathrm{~V}$ against an $\mathrm{Ag} / \mathrm{AgCl} / 1 \mathrm{M}$ aqueous $\mathrm{LiCl}$ reference electrode separated from the main electrolytic compartment by a double-fritted junction containing ACN/0.1 M TBAPF 6 . A three-electrode electrochemical cell was used with the anodic and cathodic compartments separated by a sintered glass frit. The working electrode was a glassy carbon rod (5 $\mathrm{mm}$ in diameter). Oxygen was removed before electrolysis by a stream of argon, which also passed through the stirred solution during the experiment. An Autolab PGSTAT30 potentiostat/galvanostat (Metrohm, Netherlands) was used for bulk electrolysis experiments. Solution containing 3.47 $\mathrm{mg}$ of [5] helicene was electrolyzed for $500 \mathrm{~min}$, solution containing $4.31 \mathrm{mg}$ of [6]helicene for $333 \mathrm{~min}$ and solution of $4.38 \mathrm{mg}$ of [7]helicene for $333 \mathrm{~min}$, respectively.

\section{Mass spectrometric analysis}

The electrolytic products were separated by HPLC, detected by UV spectroscopy and identified by MS spectrometry. The HPLC separation was conducted in a Dionex -UltiMate 3000 spectrometer equipped with a Luna C18(2) $150 \times 4.6 \mathrm{~mm}$ (particle size $5 \mu \mathrm{m}$ ) column (Phenomenex). The samples were dissolved in chloroform $(0.5 \mathrm{mg} / \mathrm{ml})$. The injection volume 
was $0.5 \mu 1$ and the separation was carried out in ACN (Fischer Scientifics, HPLC grade; 0.5 $\mathrm{ml} / \mathrm{min}$ ) under isocratic conditions. The UV chromatograms were detected by DAD at wavelengths of 205, 254 and $320 \mathrm{~nm}$, and recorded for $50 \mathrm{~min}$. For HRMS analysis, a Bruker micrOTOF-Q III spectrometer was used. The samples were ionized in an APCI source in positive mode. The voltages in the source were: capillary $4000 \mathrm{~V}$ and end plate offset $-500 \mathrm{~V}$; corona needle: $3000 \mathrm{nA}$. The vaporizer temperature was $400{ }^{\circ} \mathrm{C}$. For drying, the nitrogen gas was used at a flow rate of $81 / \mathrm{min}$, with a temperature of $350{ }^{\circ} \mathrm{C}$. The pressure of the nebulizer gas $\left(\mathrm{N}_{2}\right)$ was $3.5 \mathrm{Bar}$, and the collision RF was $350 \mathrm{Vpp}$. MS chromatograms were recorded for $50 \mathrm{~min}$. The HRMS spectra were measured from 33 to $1550 \mathrm{~m} / \mathrm{z}$ and calibrated with the ES-TOF-(pos) tuning mix (Fluka), which was added to the source at the beginning of each run.

\section{Atomic force microscopy}

The topography of the ITO samples was obtained with a Bruker Dimension Icon AFM microscope using the PeakForce mode of measurement and using soft sharp ScanAsystAir $(\mathrm{f}=70 \mathrm{kHz} ; \mathrm{k}=0.4 \mathrm{~N} / \mathrm{m})$ tips under ambient conditions. All samples were measured at a scale of $1 \times 1 \mu \mathrm{m}^{2}$ to visualize the detail of the structure of the samples. In addition, areas of $20 \times 20$ $\mu \mathrm{m}^{2}$ and $5 \times 5 \mu \mathrm{m}^{2}$ were analyzed to properly evaluate the overall roughness and morphology of the surfaces.

\section{Raman spectroscopy and ellipsometry of helicene layers on ITO}

Unpolarized Raman spectra were collected using a Renishaw RM 1000 (excitation of 514.5 $\mathrm{nm}$ and $633 \mathrm{~nm}$ ) and a Renishaw inVia Reflex (325 nm excitation) micro-Raman spectrometer, both operating in a standard back-scattering configuration. The Rayleigh stray light was suppressed using Edge filters. The laser beam was focused on a $\sim 2 \mu \mathrm{m}$ spot. To 
minimize sample degradation caused by the intense focused beam, a reduced laser power of $10 \mathrm{~mW}(514.5 \mathrm{~nm})$ and $2.5-25 \mathrm{~mW}(325 \mathrm{~nm})$ was applied.

The optical properties of the prepared samples were studied using an M2000 spectral ellipsometer (J.A.Woollam). The ellipsometric angles were measured in the spectral range from 245 to $1690 \mathrm{~nm}$ at a fixed incident angle of $75^{\circ}$. First, the ITO undercoating was characterized using a dispersion model composed of the Tauc-Lorentz and Drude models. The ITO coating exhibits a gradual profile of optical constants that was parametrized as an exponential decrease in the concentration of free carriers of charge in the Drude oscillator. The optical constants of [5], [6] and [7]helicene coatings were parametrized using a CodyLorentz dispersion model. The obtained ellipsometric data were analyzed and fitted to the described model. The estimated thickness is a result of the fitting process being one of the model parameters. Nevertheless, the thickness might be partially correlated with the parameters that describe the optical constants. This effect increases the ambiguity of the results. We evaluated the thickness error to be less than $10 \%$ and the refractive index error less than $2 \%$.

\section{Electronic circular dichroism}

Electronic circular dichroism $\left(\mathrm{ECD}\right.$, in $\mathrm{M}^{-1} \mathrm{~cm}^{-1}$ ) was measured in a Jasco J-815 Circular Dichroism Spectrometer (IFR140 facility - Biosit - Université de Rennes 1).

\section{Computational chemistry}

The structures of the studied molecules were optimized using density functional theory (DFT) with the hybrid three-parameter Becke-Lee-Yang-Parr (B3LYP) functional ${ }^{[35,36]}$ and with the $6-311++\mathrm{G}^{* *}$ basis set. A vibrational analysis was carried out for each structure in order to confirm whether it corresponds to a minimum on the potential energy surface. In the DFT 
calculations of the frontier orbitals, the ACN solvent was simulated with the polarizable continuum model (PCM). The ionization energies were calculated in the gas phase at the B3LYP/6-311++G** level. The adiabatic ionization energies $\left(\mathrm{IE}_{\mathrm{a}}\right)$ were calculated as the energy difference between the optimized neutral and radical cation species. The vertical ionization energies $\left(\mathrm{IE}_{\mathrm{v}}\right)$ were calculated as the energy difference between the neutral and radical cation species at the neutral state geometry. All the computations were performed with the program Gaussian $09^{[37]}$.

\section{Results and discussion}

\section{Cyclic voltammetry at GCE}

In this contribution we deal with the electrochemical characterization of [5], [6] and [7]helicenes (Fig. 1). At first, their anodic transformations were investigated in acetonitrile (ACN) supplemented with 0.1 M TBAP using GCE in the presence of oxygen. The obtained voltammograms (Fig. 1, left) indicate complex (multi-step) anodic reactions observable in the potential range from +1.5 to $+2.5 \mathrm{~V}$, distinct for each helicene in the study. In terms of the dependence of the first anodic peak of the helicenes against the square root of the scan rate $\left(v^{1 / 2}\right)$, a linear increase in the oxidation currents was observed. Based on the $\mathrm{CV}$ theory ${ }^{[38-40]}$, the results show that anodic currents relate to the electron transfer without adsorption under the experimental conditions used. We suppose that $[n]$ helicenes are subject to electrochemical transformations similar to those described previously for planar polyaromatics, a topic that is summarized in ${ }^{[41]}$. Helicene anodic reactions are most likely associated with the formation of radical cations, resulting in oligomerization or polymerization, as described, for example, for anthracene ${ }^{[42]}$.

The full CV records were performed in argon-deoxygenated supporting electrolytes to avoid oxygen reduction (Fig. 1, right). Based on an evaluation of the potentials for both 
anodic and cathodic current onsets, one can evaluate which of the helicenes undergoes electrochemical transformation more easily. For this purpose, the methodology with ferrocene as an internal standard was used ${ }^{[43]}$. The anodic current onsets for [5], [6] and [7]helicenes were at $+1410 \mathrm{mV},+1405 \mathrm{mV}$ and $+1367 \mathrm{mV}$, respectively. The respective current onsets of the major cathodic reactions were found at $-2045,-1893$ and $-1897 \mathrm{mV}$. The HOMO energy levels, estimated using anodic onsets, are in very good agreement with DFT results. Details on the electronic properties of the carbohelicenes covered in this study are summarized in Figure 2 and Table 1.

\section{Bulk electrolysis and MS analyses}

The resulting soluble oxidation products are oxygen-containing helicene derivatives, as confirmed by MS analyses of the electrolyzed solutions (Table 2 and Fig. 3). Electrolysis over a long period of 500 min for [5]helicene was insufficient for complete transformation, which was confirmed not only by CV but also by HPLC-MS. Over this long time, the charge of 1.197 C was transferred for [5] helicene, which equals to approx. transfer of one electron per molecule. Shorter electrolysis times of 333 min were used for [6]helicene and [7]helicene bulk electrolyses, during which time the total charge of $2.072 \mathrm{C}$ was transferred for [6]helicene (1.63 electrons per molecule) and 1.120 C for [7]helicene (approx. one electron per molecule). Data were not corrected for the charging current contribution, which would be the same in the same electrolytic cell used under the assumption that oxidation products do not change the electrode differential capacitance value. According to the UV chromatogram $(320 \mathrm{~nm})$, the concentration of the parent helicenes was around $90 \%$ after electrolysis. The non-exhaustive electrolysis, however, proved sufficient to obtain information regarding the soluble products of helicenes' oxidative transformations. 
Fortunately, the helicene derivatives are more easily ionized than the starting helicenes, and so the products of the electrolysis could be clearly detected by MS. The results obtained by the integration of individual peaks in HPLC-MS chromatograms (Fig. 3) are summarized in Table 2. Table 2 lists the peak areas of all the constitutional isomers of each helicene, as well as the peak area of the parent compound after electrolysis, and reports them as percentages of the total peak area. If the isostructural compounds have similar ionization properties, the yields of products obtained from each helicene can be compared. However, the integral amount of hydroxy derivatives is rather deceptive, as these compounds are also formed in the APCI source of the MS spectrometer. This feature was confirmed by measurement of the chloroform solution of starting [6]helicene under the same conditions. An interesting behavior was observed for the electrochemical dimerization reactions. While the dimerization of [5]helicene gives a variety of products with one of them highly preferred, [6]helicene does not exhibit a preference. In the electrolyzed solution of [7]helicene, only three clearly separable dimers in the 1:2:1 ratio can be observed. Acetamido derivatives were also observed, resulting from the reaction of the helicenes' radical cations with acetonitrile.

The following HRMS data were found for [5]helicene: $\mathrm{C}_{22} \mathrm{H}_{14}$ calc.: 279.1168 $\left([\mathrm{M}+\mathrm{H}]^{+}\right)$found: 279.1169 ; hydroxy[5]helicene: $\mathrm{C}_{22} \mathrm{H}_{14} \mathrm{O}$ calc.: $295.1117\left([\mathrm{M}+\mathrm{H}]^{+}\right)$found: 295.1116; [5]helicene quinone: $\mathrm{C}_{22} \mathrm{H}_{12} \mathrm{O}_{2}$ calc.: $309.0910\left([\mathrm{M}+\mathrm{H}]^{+}\right)$found: 309.0927; bis[5]helicene: $\mathrm{C}_{44} \mathrm{H}_{26}$ calc.: $555.2107\left([\mathrm{M}+\mathrm{H}]^{+}\right)$found: 555.2093; acetamido[5]helicene: $\mathrm{C}_{24} \mathrm{H}_{17} \mathrm{NO}$ calc.: $336.1382\left([\mathrm{M}+\mathrm{H}]^{+}\right)$found: 336.1377 : for [6]helicene: $\mathrm{C}_{26} \mathrm{H}_{16}$ calc.: 329.1324 $\left([\mathrm{M}+\mathrm{H}]^{+}\right)$found: 329.1307 ; hydroxy[6]helicene: $\mathrm{C}_{26} \mathrm{H}_{16} \mathrm{O}$ calc.: $345.1273\left([\mathrm{M}+\mathrm{H}]^{+}\right)$found: 345.1263; [6]helicene quinone: $\mathrm{C}_{26} \mathrm{H}_{14} \mathrm{O}_{2}$ calc.: $359.1066\left([\mathrm{M}+\mathrm{H}]^{+}\right)$found: 359.1054 ; bis[6]helicene: $\mathrm{C}_{52} \mathrm{H}_{30}$ calc.: $655.2220\left([\mathrm{M}+\mathrm{H}]^{+}\right)$found: 655.2200 ; acetamido[6]helicene: $\mathrm{C}_{28} \mathrm{H}_{19} \mathrm{NO}$ calc.: $386.1539\left([\mathrm{M}+\mathrm{H}]^{+}\right)$found: 386.1521 ; and for [7]helicene: $\mathrm{C}_{30} \mathrm{H}_{18}$ calc. $379.1481\left([\mathrm{M}+\mathrm{H}]^{+}\right)$found: 379.1481 ; hydroxy[7]helicene: $\mathrm{C}_{30} \mathrm{H}_{18} \mathrm{O}$ calc.: $395.1430\left([\mathrm{M}+\mathrm{H}]^{+}\right)$ 
found: 395.1427; [7]helicene quinone: $\mathrm{C}_{30} \mathrm{H}_{16} \mathrm{O}_{2}$ calc.: $409.1223\left([\mathrm{M}+\mathrm{H}]^{+}\right)$found: 409.1214; bis[7]helicene: $\mathrm{C}_{60} \mathrm{H}_{34}$ calc.: $755.2733\left([\mathrm{M}+\mathrm{H}]^{+}\right)$found: 755.2714 ; acetamido[7]helicene: $\mathrm{C}_{32} \mathrm{H}_{21} \mathrm{NO}$ calc.: $436.1695\left([\mathrm{M}+\mathrm{H}]^{+}\right)$found: 436.1670.

\section{Anodic deposition of helicenes onto ITO electrodes}

It was previously shown that helicenes can be immobilized through an electropolymerizable substituent with conducting properties in the form of compact layers using anodic electrosynthesis, and such deposits could find applications in optoelectronics and in the field of spectroelectrochemical sensing ${ }^{[26]}$. Here we present the electrochemical preparation of compact layers of parent helicenes. During repeated anodization of the electrode immersed in $1 \mathrm{mM}$ helicene solution, a decrease in $\mathrm{CV}$ peak height was observed, indicating the passivation of the electrode surface and formation of a deposit on the electrode surface. It was found that helicene layers are fully compact, as confirmed using redox Fe/Ru markers ${ }^{[33]}$. Under the conditions used, the resulting films are overoxidized similarly to layers previously reported in ref. ${ }^{[13]}$. The aforementioned layers were prepared on the ITO electrode and subjected to spectroscopic and microscopic characterization according to the methodology given elsewhere $^{[26]}$. It has been confirmed that it is possible to fabricate thin helicene films on conductive substrates in this way (Fig. 4). For investigating the surface chemistry, Raman spectra of ITO slides covered with helicene layers were recorded at a wavelength of $325 \mathrm{~nm}$ (Fig. 5A). The layers deposited onto ITO electrodes exhibit the typical Raman characteristics observed for several carbon nanostructured materials, featuring the so-called G band around $1600 \mathrm{~cm}^{-1}$, which are associated with $\mathrm{sp}^{2}$ hybridized carbons and the characteristic $\mathrm{sp}^{3}$ carbon band around $1340 \mathrm{~cm}^{-1}$ (D band) ${ }^{[33]}$.

Ellipsometric measurements were performed using helicene-coated ITO slides as well. Thickness and optical functions were obtained by fitting to the appropriate model. The 
thickness of the racemic [5], [6] and [7]helicene layers was estimated to be $46 \mathrm{~nm}, 62 \mathrm{~nm}$ and $55 \mathrm{~nm}$, respectively. The thickness of layers prepared from both $\mathrm{P}$ and $\mathrm{M}$ [6]helicene enantiomers was $40 \mathrm{~nm}$ and $37 \mathrm{~nm}$, respectively. Optical functions of the electrodeposited helicene layers are depicted in Fig. 5B,C. There is an absorption edge in the UV range below $400 \mathrm{~nm}$ that is parameterized using a Cody-Lorentz dispersion model. This absorption edge of [7]helicene is significantly shifted to longer wavelengths with respect to the other samples. This behavior indicates a reduced HOMO-LUMO band gap of [7]helicene. The racemic [5], [6] and [7]helicene layers exhibit enhanced absorption in the visible and near-infrared range, which can be seen in the graph of extinction coefficient in Fig. 5C. This behavior was parameterized using additional Lorentz oscillators included in the dispersion model. In contrast, the pure enantiomers exhibit zero absorption in the visible and near-infrared range.

The refractive index of all samples exhibits normal dispersion behavior, with a flat appearance in the visible and near-infrared range that is followed by a sudden increase in the ultraviolet region. The refractive index of the racemic [6]helicene layer is around 1.63 in the visible and near-infrared range, whereas the [5] and [7]helicene layers exhibit an enhanced refractive index of just below 1.7 . The $\mathrm{M}$ enantiomer exhibits a slightly reduced refractive index, while the $\mathrm{P}$ enantiomer exhibits a slightly enhanced refractive index with respect to the racemic [6]helicene layer.

\section{Chiral [6] helicene layers and CD spectroscopy}

Finally, we focused on the characterization of chiral $[n]$ helicene layers at ITO electrodes prepared in the same way as described above for the racemic mixtures. Due to the low racemization barrier, it is evident that the preparation of [5]helicene enantiomers is not efficient for further applications. Thus, the experiments were performed with $P$ and $M$ enantiopure forms of [6]helicene and [7]helicene. Of them only [6]helicene electrosynthesis 
resulted in the formation of layers with chiroptical properties under the experimental conditions used, which was confirmed using electronic circular dichroism (CD) spectroscopy.

Figure 6A shows the UV-Vis response of the films obtained from $P$-and $M$-[6]helicene as red and blue curves, respectively. The dotted spectra correspond to the measurement on the opposite face of the films. Note that below $300 \mathrm{~nm}$ the neat support absorbs too much and therefore prevents any measurement. Different films were prepared from solutions of different concentrations, see CD spectra for the $M$-layers in Figure 7 . The films obtained by the electrosynthesis of $5 \mathrm{mM}$ solutions were chosen for detailed measurements of their chiroptical properties (UV-Vis and CD spectra).

The UV-Vis spectra in the $300-600 \mathrm{~nm}$ region show one absorption band centered at $305 \mathrm{~nm}$ with absorbance values between 0.1 and 0.3 , and one broad band around $450 \mathrm{~nm}$ with absorbance values between 0.001 and 0.006 . Since the baseline absorbance measurements shown in Figure 7B appeared to be highly reproducible, we can hypothesize that the different absorbance values obtained in the UV-Vis spectra could be caused by different local thicknesses of the films.

Figure 6B shows the $\mathrm{CD}$ response in the $300-600 \mathrm{~nm}$ region of the films obtained from $P$-and $M$-carbo[6]helicene as red and blue curves respectively. In order to see some linear birefringence, $\mathrm{CD}$ measurements of the samples rotated by $180^{\circ}$ were also recorded, but no difference was observed. From Figure 6B, one can clearly see a positive (or negative) CDactive band around $310 \mathrm{~nm}$ for the $P$-layer (or $M$-layer). This band exhibiting strong ellipticity (between -10 and +6 ) may be assigned to the typical $\pi-\pi^{*}$ transitions found at $325 \mathrm{~nm}$ in the carbo[6]helicene monomer (see Figure 8). A blue shift is therefore observed upon electrosynthesis.

In addition and very interestingly, new CD-active bands appeared between 380 and $580 \mathrm{~nm}$, as emphasized in Figure 6C, showing a negative-positive (or positive-negative) 
signature for the $P$-layer (or $M$-layer). More precisely, the $P$-layer exhibits a negative CDactive band at $390 \mathrm{~nm}$ with ellipticity values around -0.5 and a positive CD-active band around $475 \mathrm{~nm}$ with ellipticity values around +0.5 . Since such a signature is not present in the parent carbo[6]helicene enantiomers, we can assign these new bands to the deposited layers. To the best of our knowledge, the appearance of a clear bisignate signature in a helicenic electrodeposited structure has never been observed before ${ }^{[23-25,44]}$.

\section{Conclusions and Further Remarks}

The electrochemical properties of three helical polyaromatics [5]helicene, [6]helicene and [7]helicene were studied. Despite the fact that the carbohelicenes are composed only of nonsubstituted ortho-condensed benzene rings (building blocks), their electrochemical properties are significantly different. The helicenes were studied as racemic equimolar mixtures of $P$ and $M$ enantiomers using a glassy carbon electrode. Based on oxidation and reduction $E_{\mathrm{p}}$ values, it is evident that [7]helicene is oxidized more easily than [5] or [6]helicene. These findings are in good agreement with ionization potential DFT calculations ${ }^{[35,36]}$. The above results will be applicable in the study of other carbohelicenes and for improving our understanding of the redox transformations of chiral polyaromatics as well as extended $\pi$-conjugated molecular systems in general, which is important for organic electronics applications ${ }^{[45]}$.

Electrochemical analyses of the helicenes were performed under non-aqueous conditions with a supporting electrolyte of ACN/0.1 M TBAP. Their anodic reactions are diffusion-controlled processes, which result in the growth of oligomeric or polymeric structures at the electrode surface. This process corresponds to the formation of hydroxy/quinone derivatives and dimeric structures identified via bulk electrolysis and liquid chromatography/mass spectrometry. The electrosynthesized layers formed by oxidative deposition onto the transparent ITO electrode surfaces were subsequently analyzed using 
Raman spectroscopy, which confirmed the typical D and G characteristics for carbon materials ${ }^{[33]}$. The morphology of the helicene layers and their thickness were revealed by AFM imaging as well as ellipsometrically. It was found that helicene layers are isotropic in nature and fully compact.

Using CD spectroscopy, it was also demonstrated that the $P$ and $M$ enantiomers of [6]helicene can be immobilized electrochemically to form chiral (enantiopure) thin layers on the ITO substrate, and that these layers exhibit new CD signatures compared to the parent [6]helicene. The electrodeposition of helicenes should be further optimized for the purposes of preparing conductive layers ${ }^{[26]}$ and components of electronics devices.

The future direction of our research will be to develop new carbohelicene functional derivatives and their synthesis at the multi-gram scale ${ }^{[15,29]}$. The main focus of attention will be on the study of redox transformations and the electrodeposition of optically pure $(P / M$ enantiomeric) versions of other helicene derivatives. In the electrosynthetic approach, we will focus on the transfer of prepared layers from conductive onto non-conductive substrates according to a recently developed protocol ${ }^{[26]}$ and modulation of the experimental conditions (time-dependent parameters such as scan rate and number of CV scans) for the electrosynthesis of tailored helicene-based layers and new composite materials.

\section{Acknowledgments}

The authors would like to thank Dr. P. Cuřínová (ICPF ASCR) for technical support, especially for LC-MS analysis. This work was financed by the Institutional Support of Palacky University in Olomouc (J.V.) by the National Grid Infrastructure MetaCentrum (LM2010005, J.St. and T.S.), by the MEYS (projects LO1409, J.B., LD15058, J.H. and LM2015088, L.F.), by the FUNBIO (CZ.2.16/3.1.00/21568, L.F.), by the Technology Agency of the Czech Republic (TA04010082, J.St.), and by the Czech Science Foundation (17- 
02578S, V.C. and 15-12719S T.S. and J.Sy.). J.C. wishes to thank Ministère de l'Education Nationale, de la Recherche et de la Technologie, Centre National de la Recherche Scientifique (CNRS), and the PRISM core facility (Biogenouest $\odot$, UMS Biosit, Université de Rennes 1 Campus de Villejean - 35043 RENNES Cedex, FRANCE). The authors are indebted to Mr. Ben Watson-Jones MEng for language correction. 


\section{References}

[1] M. Gingras, Chem. Soc. Rev. 2013, 42, 1051-1095.

[2] M. Gingras, Chem. Soc. Rev. 2013, 42, 968-1006.

[3] M. Gingras, G. Felix and R. Peresutti, Chem. Soc. Rev. 2013, 42, 1007-1050.

[4] C.-F. Chen and Y. Shen, Helicene Chemistry: From Synthesis to Applications. Springer, Heidelberg 2016.

[5] M. Li, H.-Y. Lu, R.-L. Liu, J.-D. Chen and C.-F. Chen, J. Org. Chem. 2012, 77, 36703673.

[6] K.-I. Shinohara, Y. Sannohe, S. Kaieda, K.-I. Tanaka, H. Osuga, H. Tahara, Y. Xu, T. Kawase, T. Bando and H. Sugiyama, J. Am. Chem. Soc. 2010, 132, 3778-3782.

[7] D. Z. Wang and T. J. Katz, J. Org. Chem. 2005, 70, 8497-8502.

[8] A. J. Lovinger, C. Nuckolls and T. J. Katz, J. Am. Chem. Soc. 1998, 120, 264-268.

[9] K. Nakano, H. Oyama, Nishimura, S. Nakasako and K. Nozaki, Angew. Chem. Int. Ed. 2012, 51, 695-699.

[10] M. T. Reetz and S. Sostmann, Tetrahedron 2001, 57, 2515-2520.

[11] M. A. Shcherbina, X. b. Zeng, T. Tadjiev, G. Ungar, S. Eichhorn, K. Phillips and T. J. Katz, Angew. Chem. Int. Ed. Engl. 2009, 48, 7837-7840.

[12] E. Anger, M. Srebro, N. Vanthuyne, L. Toupet, S. Rigaut, C. Roussel, J. Autschbach, J. Crassous and R. Réau, J. Am. Chem. Soc. 2012, 134, 15628-15631.

[13] J. Hrbac, J. Storch, V. Halouzka, V. Cirkva, P. Matejka and J. Vacek, RSC Adv. 2014, 4, 46102-46105.

[14] L. Q. Shi, Z. Liu, G. F. Dong, L. Duan, Y. Qiu, J. Jia, W. Guo, D. Zhao, D. L. Cui and X. T. Tao, Chem. Eur. J. 2012, 18, 8092-8099.

[15] J. Storch, J. Zadny, T. Strasak, M. Kubala, J. Sykora, M. Dusek, V. Cirkva, P. Matejka, M. Krbal and J. Vacek, Chem. Eur. J. 2015, 21, 2343-2347.

[16] Y. Yang, R. C. da Costa, M. J. Fuchter and A. J. Campbell, Nat. Photonics 2013, 7, 634638.

[17] Y. Yang, R. C. da Costa, D. M. Smilgies, A. J. Campbell and M. J. Fuchter, Adv. Mater. 2013, 25, 2624-2628.

[18] S. Grimme, J. Harren, A. Sobanski and F. Vogtle, Eur. J. Org. Chem. 1998, 1491-1509.

[19] J. R. Brandt, X. Wang, Y. Yang, A. J. Campbell and M. J. Fuchter, J. Am. Chem. Soc. 2016, 138, 9743-9746.

[20] T. Kaseyama, S. Furumi, X. Zhang, K. Tanaka and M. Takeuchi, Angew. Chem. Int. Ed. 2011, 50, 3684-3687. 
[21] Y. H. Kim, B. Yoo, J. E. Anthony and S. K. Park, Adv. Mater. 2012, 24, 497-+.

[22] K. Moth-Poulsen and T. Bjornholm, Nat. Nanotechnol. 2009, 4, 551-556.

[23] Y. Dai, T. J. Katz and D. A. Nichols, Angew. Chemie Int. Ed. 1996, 35, 2109-2111.

[24] J. M. Fox, D. Lin, Y. Itagaki and T. Fujita, J. Org. Chem. 1998, 63, 2031-2038.

[25] E. Anger, H. Iida, T. Yamaguchi, K. Hayashi, D. Kumano, J. Crassous, N. Vanthuyne, C. Roussel and E. Yashima, Polym. Chem. 2014, 5, 4909-4914.

[26] J. Hrbac, T. Strasak, L. Fekete, V. Ladanyi, J. Pokorny, J. Bulir, M. Krbal, J. Zadny, J. Storch and J. Vacek, ChemElectroChem 2017, 4, 3047-3052.

[27] L. Rulisek, O. Exner, L. Cwiklik, P. Jungwirth, I. Stary, L. Pospisil and Z. Havlas, J. Phys. Chem. C 2007, 111, 14948-14955.

[28] L. Liu and T. J. Katz, Tetrahedron Lett. 1991, 32, 6831-6834.

[29] J. Storch, J. Sykora, J. Cermak, J. Karban, I. Cisarova and A. Ruzicka, J. Org. Chem. 2009, 74, 3090-3093.

[30] A. Sudhakar and T. J. Katz, Tetrahedron Lett. 1986, 27, 2231-2234.

[31] J. Storch, K. Kalikova, E. Tesarova, V. Maier and J. Vacek, J. Chromatogr. A 2016, $1476,130-134$.

[32] C. Fraser and B. Bosnich, Inorg. Chem. 1994, 33, 338-346.

[33] R. L. McCreery, Chem. Rev. 2008, 108, 2646-2687.

[34] J. Hrbac, V. Halouzka, L. Trnkova and J. Vacek, Sensors (Switzerland) 2015, 14, 1394313954.

[35] A. D. Becke, J. Chem. Phys. 1993, 98, 5648-5652.

[36] C. Lee, W. Yang and R. G. Parr, Phys. Rev. B 1988, 37, 785-789.

[37] M. J. Frisch, G. W. Trucks, H. B. Schlegel, G. E. Scuseria, M. A. Robb, J. R. Cheeseman, G. Scalmani, V. Barone, B. Mennucci, G. A. Petersson, H. Nakatsuji, M. Caricato, X. Li, H. P. Hratchian, A. F. Izmaylov, J. Bloino, G. Zheng, J. L. Sonnenberg, M. Hada, M. Ehara, K. Toyota, R. Fukuda, J. Hasegawa, M. Ishida, T. Nakajima, Y. Honda, O. Kitao, H. Nakai, T. Vreven, J. J. A. Montgomery, J. E. Peralta, F. Ogliaro, M. Bearpark, J. J. Heyd, E. Brothers, K. N. Kudin, V. N. Staroverov, R. Kobayashi, J. Normand, K. Raghavachari, A. Rendell, J. C. Burant, S. S. Iyengar, J. Tomasi, M. Cossi, N. Rega, J. M. Millam, M. Klene, J. E. Knox, J. B. Cross, V. Bakken, C. Adamo, J. Jaramillo, R. Gomperts, R. E. Stratmann, O. Yazyev, A. J. Austin, R. Cammi, C. Pomelli, J. W. Ochterski, R. L. Martin, K. Morokuma, V. G. Zakrzewski, G. A. Voth, P. Salvador, J. J. Dannenberg, S. Dapprich, A. D. Daniels, O. Farkas, J. B. Foresman, J. V. Ortiz, J. Cioslowski and D. J. Fox, Gaussian 09, Revision A.1, Gaussian, Inc., Wallingford CT 2009. 
[38] A. M. Bond, Modern Polarographic Methods in Analytical Chemistry, Marcel Dekker, New York 1980.

[39] V. Lazarescu, Cyclic voltammetry at electrode surfaces, In: Encyclopedia of Surface and Colloid Science (Eds.: P. Somasundaran and A. Hubbard), Taylor \& Francis 2006, 15951632.

[40] R. S. Nicholson and I. Shain, Anal. Chem. 1965, 36, 706-723.

[41] O. Hammerich, Anodic oxidation of hydrocarbons in Organic Electrochemistry, 4th ed. rev. and exp., Lund H. and Hammerich O. (eds.), Marcel Dekker Inc. 2001, 471-498.

[42] J. O. Howell and R. M. Wightman, J. Phys. Chem. 1984, 88, 3915-3918.

[43] A. Magri, P. Friederich, B. Schafer, V. Fattori, X. Sun, T. Strunk, V. Meded, L. E. Hueso, W. Wenzel and M. Ruben, Beilstein J. Nanotechnol. 2015, 6, 1107-1115.

[44] L.-L. Zhou, M. Li, H.-Y. Lu and C.-F. Chen, Polym. Chem. 2016, 7, 310-318.

[45] H. Hopf, Chem. Rec. 2014, 14, 979-1000.

[46] S. Obenland and W. Schmidt, J. Am. Chem. Soc. 1975, 97, 6633-6638. 


\section{TABLES:}

Table 1: Overview of HOMO and LUMO energy levels, HOMO-LUMO gaps and ionization potential energies (IE) of [5], [6], and [7]helicenes (in eV). For other details, see Fig. 2.

\begin{tabular}{|c|c|c|c|c|c|c|c|}
\hline & $\begin{array}{l}\text { HOMO } \\
\text { (calc.) }\end{array}$ & HOMO(exp. $)^{1}$ & $\begin{array}{l}\text { LUMO } \\
\text { (calc.) }\end{array}$ & $\begin{array}{l}\text { HOMO- } \\
\text { LUMO } \\
\text { gap } \\
\text { (calc.) }\end{array}$ & $\begin{array}{l}\mathrm{IE}_{\mathrm{a}} \\
\text { (calc.) }\end{array}$ & $\begin{array}{l}\mathrm{IE}_{\mathrm{v}} \\
\text { (calc.) }\end{array}$ & $\mathrm{IE}_{\mathrm{v}}(\exp .)^{2}$ \\
\hline [5]helicene & -5.97 & -5.81 & -1.85 & 4.12 & 7.11 & 7.21 & 7.51 \\
\hline [6]helicene & -5.93 & -5.80 & -2.02 & 3.91 & 6.98 & 7.07 & 7.37 \\
\hline [7]helicene & -5.91 & -5.77 & -2.06 & 3.81 & 6.85 & 6.96 & 7.25 \\
\hline
\end{tabular}

The adiabatic ionization energies $\left(\mathrm{IE}_{\mathrm{a}}\right)$ were calculated as the energy difference between the optimized neutral and radical cation species. The vertical ionization energies $\left(\mathrm{IE}_{\mathrm{v}}\right)$ were calculated as the energy difference between the neutral and radical cation species in the neutral state geometry. Based on ${ }^{1}$ ) electrochemical data shown in Fig. 1 and on ${ }^{2}$ ) ref. ${ }^{[46]}$. 
Table 2: Percentual distribution of oxidation electrolytic products of [5], [6], and [7]helicenes. Parent compound and sum of oxidation products equals $100 \%$. The electrolysis was performed with $1 \mathrm{mM}$ helicenes in acetonitrile / $0.1 \mathrm{M}$ tetrabutylammonium hexafluorophosphate at $E=+2.5 \mathrm{~V}$ (vs. $\mathrm{Ag} / \mathrm{AgCl} / 1 \mathrm{M} \mathrm{LiCl}_{\mathrm{aq}}$ ) for 500 (for [5]helicene) and $333 \mathrm{~min}$ (for [6] and [7]helicenes) using a high-surface-area GC electrode. For other details, see Fig. 3.

\begin{tabular}{lccccc}
\hline & {$[\mathrm{M}+\mathrm{H}]^{+}$} & {$[\mathrm{M}+\mathrm{OH}+\mathrm{H}]^{+}$} & {$[\mathrm{M}+2 \mathrm{O}+\mathrm{H}]^{+}$} & {$\left[\mathrm{M}+\mathrm{NHCOCH}{ }_{3}+\mathrm{H}\right]^{+}$} & {$[2 \mathrm{M}+\mathrm{H}]^{+}$} \\
\hline [5]helicene & 68.75 & 0.48 & 0.49 & 0.22 & 30.06 \\
[6]helicene & 89.76 & 0.56 & 0.46 & 0.15 & 9.07 \\
[7]helicene & 95.29 & 1.15 & 0.40 & 0.07 & 3.09 \\
\hline
\end{tabular}




\section{FIGURE LEGENDS:}

Fig. 1. Anodic (left) and full (right) CV records of $1 \mathrm{mM}$ [5]helicene (A), [6]helicene (B) and [7]helicene (C) at GCE in acetonitrile/0.1M tetrabutylammonium perchlorate electrolyte. CV parameters: scan rate $100 \mathrm{mV} / \mathrm{s}, E_{\text {init }} 0 \mathrm{~V} / E_{\text {vertex }}+2.5 \mathrm{~V}$ (for anodic records) and $E_{\text {init }} 0 \mathrm{~V} / E_{\text {first }}$ vertex $-3 \mathrm{~V} / E_{\text {second vertex }} 2.5 \mathrm{~V}$ (for full scans), vs. $\mathrm{Ag} / \mathrm{AgCl} / 3 \mathrm{M} \mathrm{KCl}$. Blank electrolytes (ele; highlighted by grey dashed lines) were deoxygenated with argon for full CV records.

Fig. 2. Calculated HOMO and LUMO energy levels for $[n]$ helicenes. For other details, see Table 1.

Fig. 3. HPLC chromatogram of the electrolytic products of [5]helicene (red), [6]helicene (blue) and [7]helicene (green) obtained with UV detection at $320 \mathrm{~nm}$. MS traces of hydroxyderivatives (A), quinonic derivatives (B), acetamidoderivatives (C) and dimers (D) of each helicene are depicted. The electrolysis was performed with $1 \mathrm{mM}$ helicenes in acetonitrile/0.1 M tetrabutylammonium hexafluorophosphate using a high-surface area GC electrode. For other details, see Table 2.

Fig. 4. Cyclic voltammograms (A) of $1 \mathrm{mM}$ helicenes performed in acetonitrile/0.1 M TBAP at ITO electrodes. CV parameters: $E_{\text {init }} 0 \mathrm{~V}$, vertex potential $+2.5(v s . \mathrm{Ag} / \mathrm{AgCl} / 3 \mathrm{M} \mathrm{KCl})$; scan rate $100 \mathrm{mV} \mathrm{s}^{-1}$. Inset: ITO substrate covered with electrodeposited helicene structures; helicene-covered area is darker than bare unmodified electrode. (B) AFM images of helicenecovered ITO slides. 
Fig. 5. Raman spectra of bare and helicene-covered ITO slides (A). Ellipsometric results expressed as dependence of refractive index (B) and extinction coefficient (C) on wavelength.

Fig. 6. (A) Absorbance spectra and (B) CD spectra of layers obtained by anodic electrodeposition of $5 \mathrm{mM} P$ and $M$-carbo[6]helicenes. Both faces of each film were measured. (C) Selected region between 380-580 nm highlighting the negative-positive (or positive-negative) signature for $P$-layer (or $M$-layer). All the spectra have been baseline subtracted.

Fig. 7. (A) CD spectra in ellipticity units of baselines (naked ITO supports) and (B) corresponding UV-Vis spectra. (C) CD spectra of $M$-layers obtained by electrosynthesis in solutions of [6]helicene monomers at $1-5 \mathrm{mM}$ concentrations.

Fig. 8. $\mathrm{CD}$ and UV-Vis spectra of parent carbo[6]helicene enantiomers $\left(\mathrm{CH}_{2} \mathrm{Cl}_{2}, \mathrm{C} \sim 4 \times 10^{-5}\right.$ M). 


\section{FIGURES:}

Fig. 1.
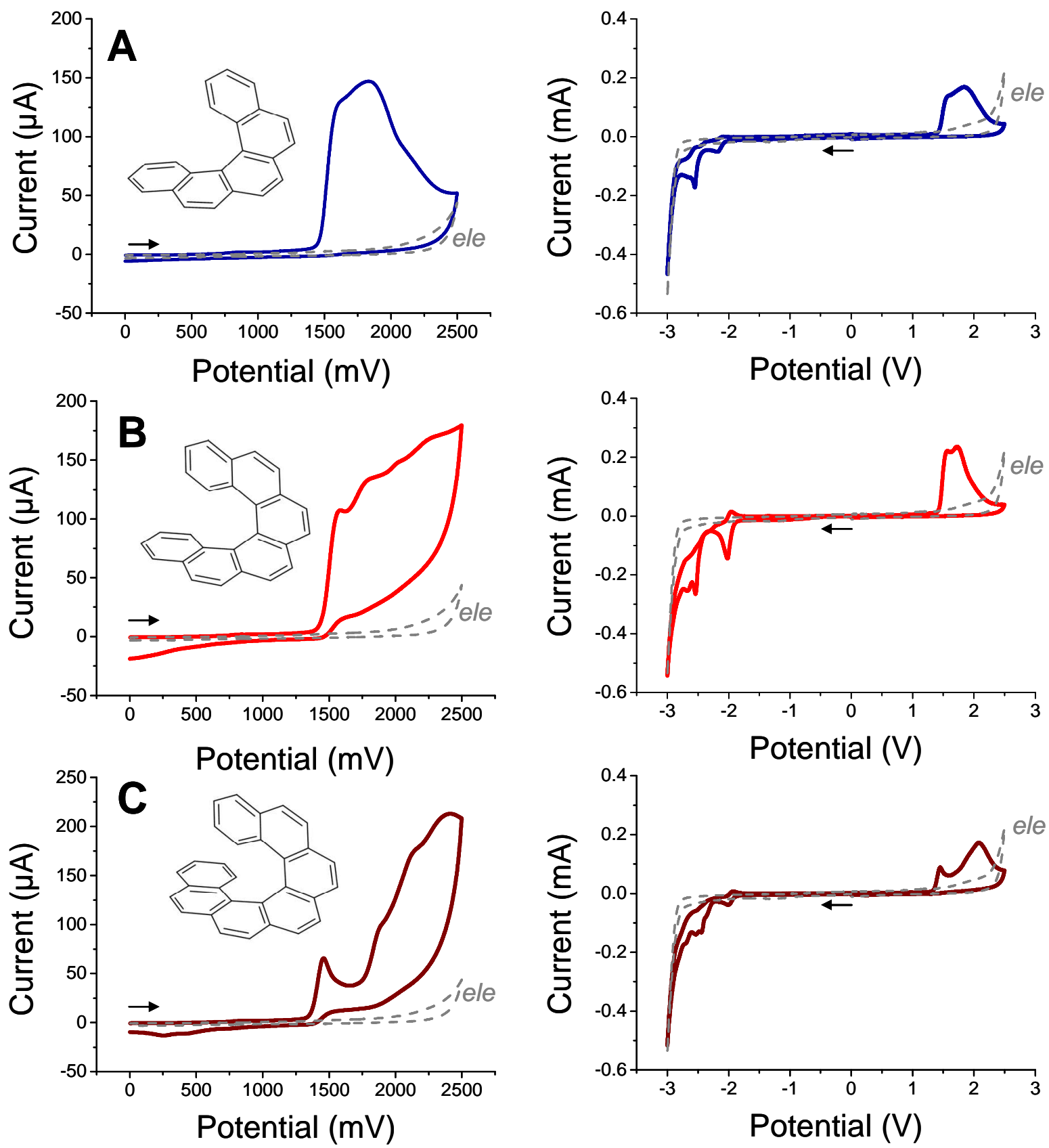
Fig. 2.
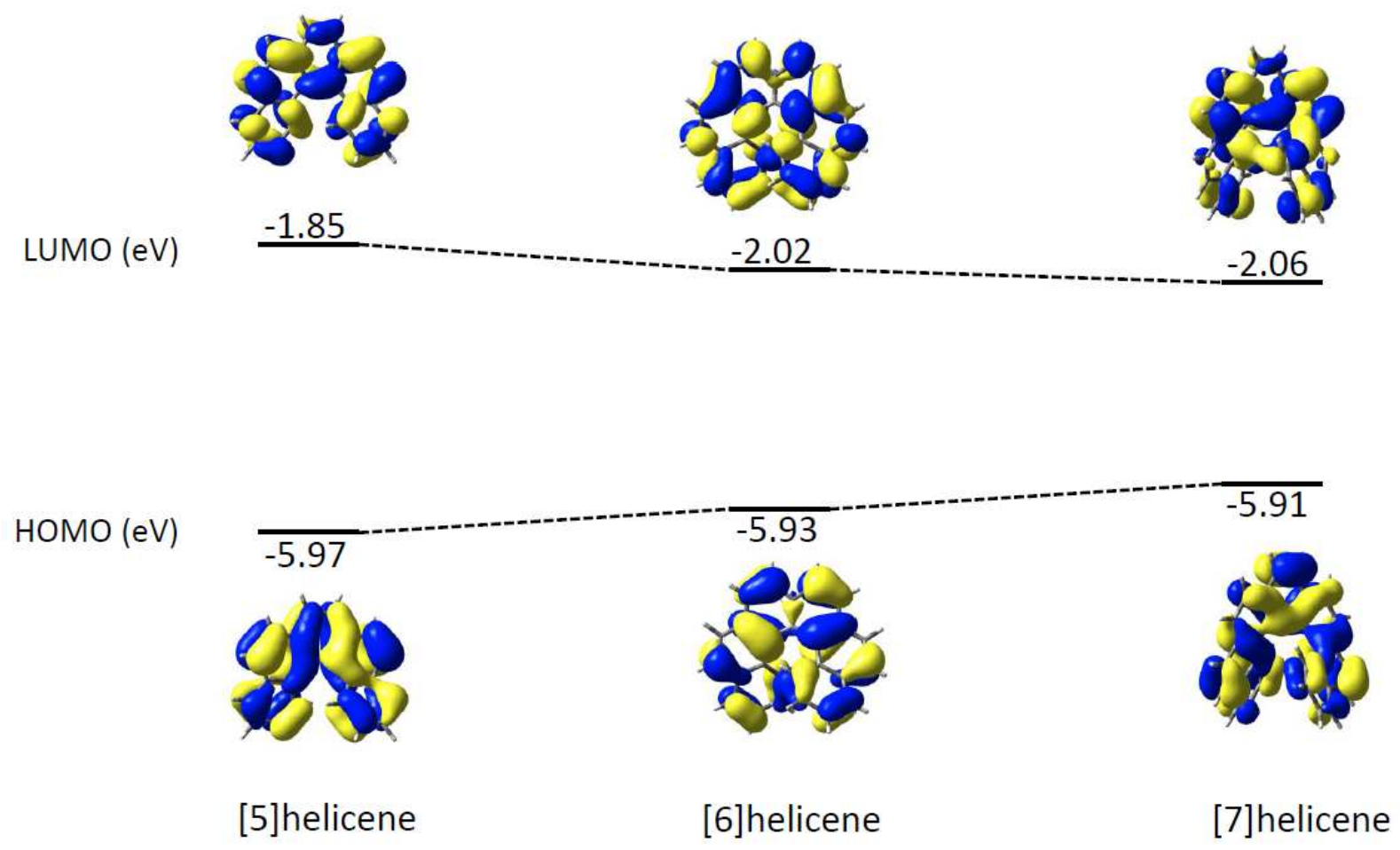
Fig. 3.

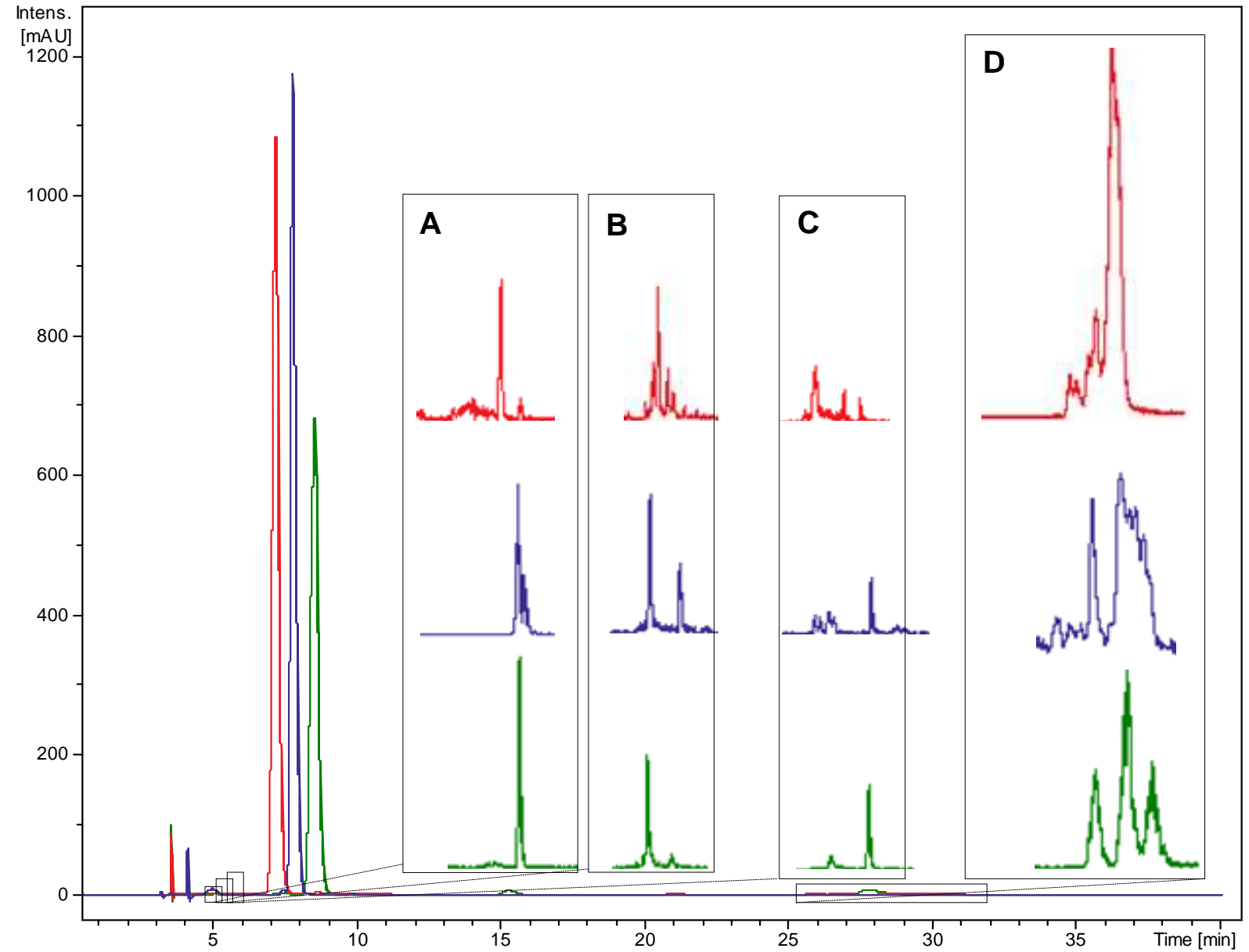


Fig. 4.
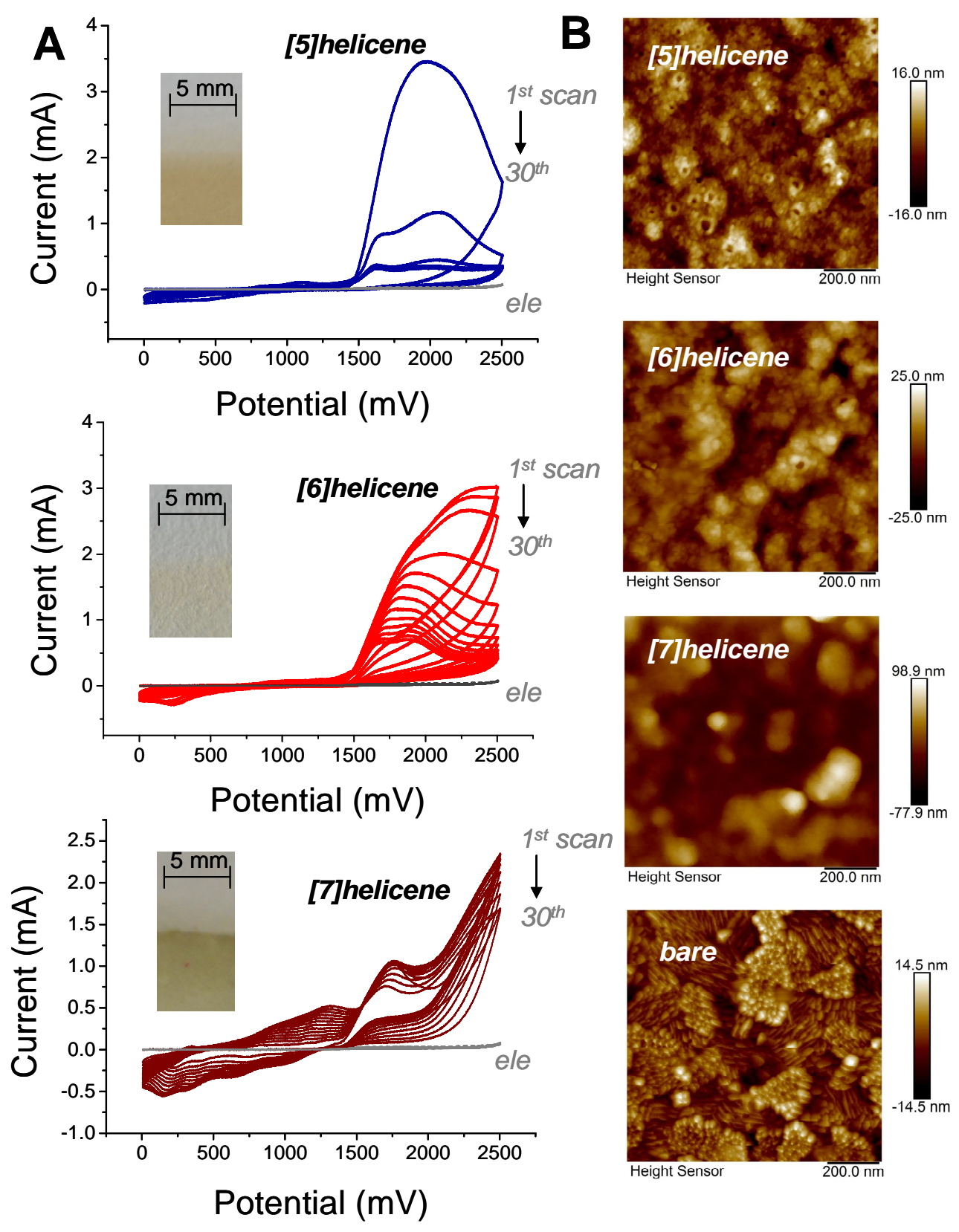
Fig. 5.
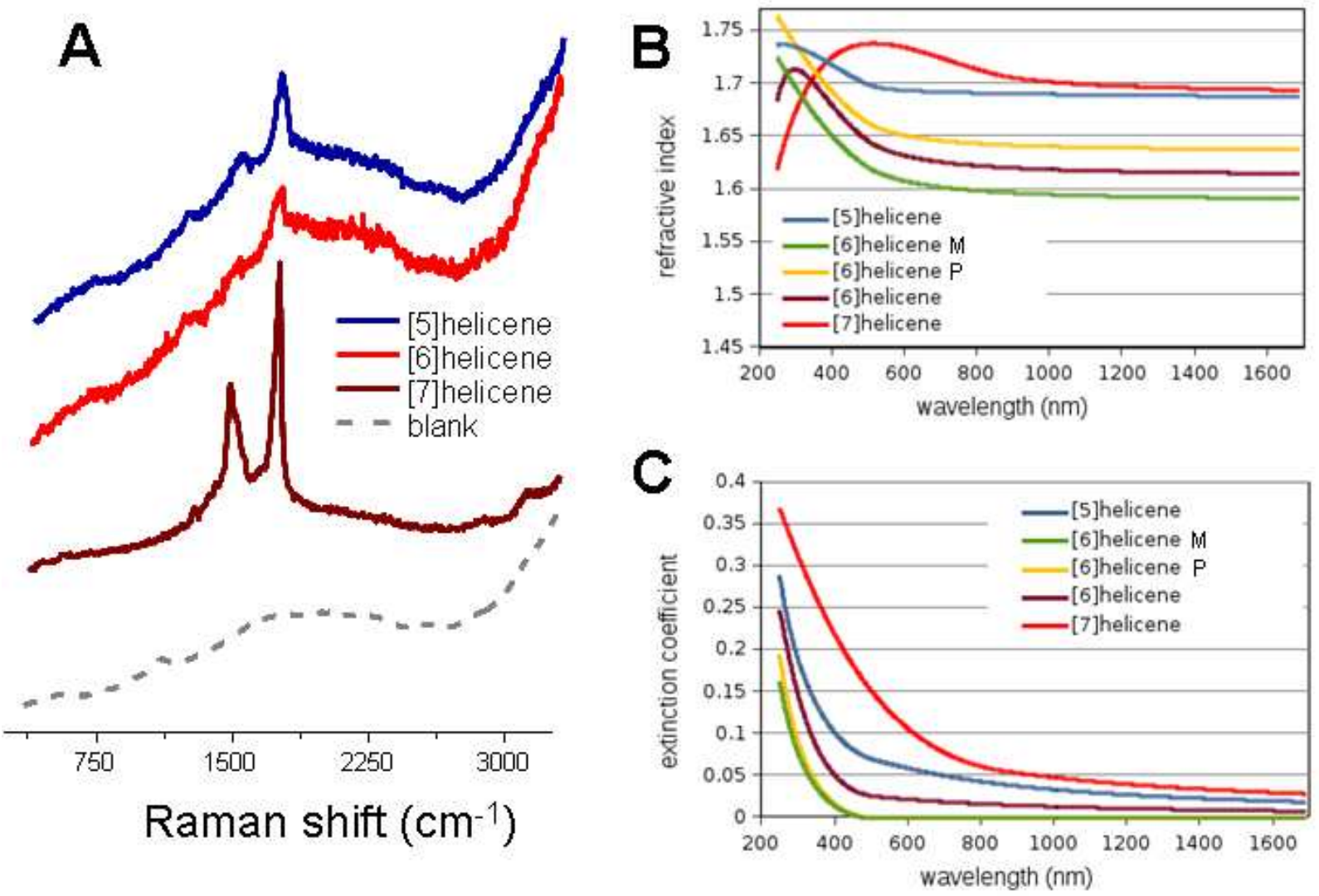
Fig. 6.
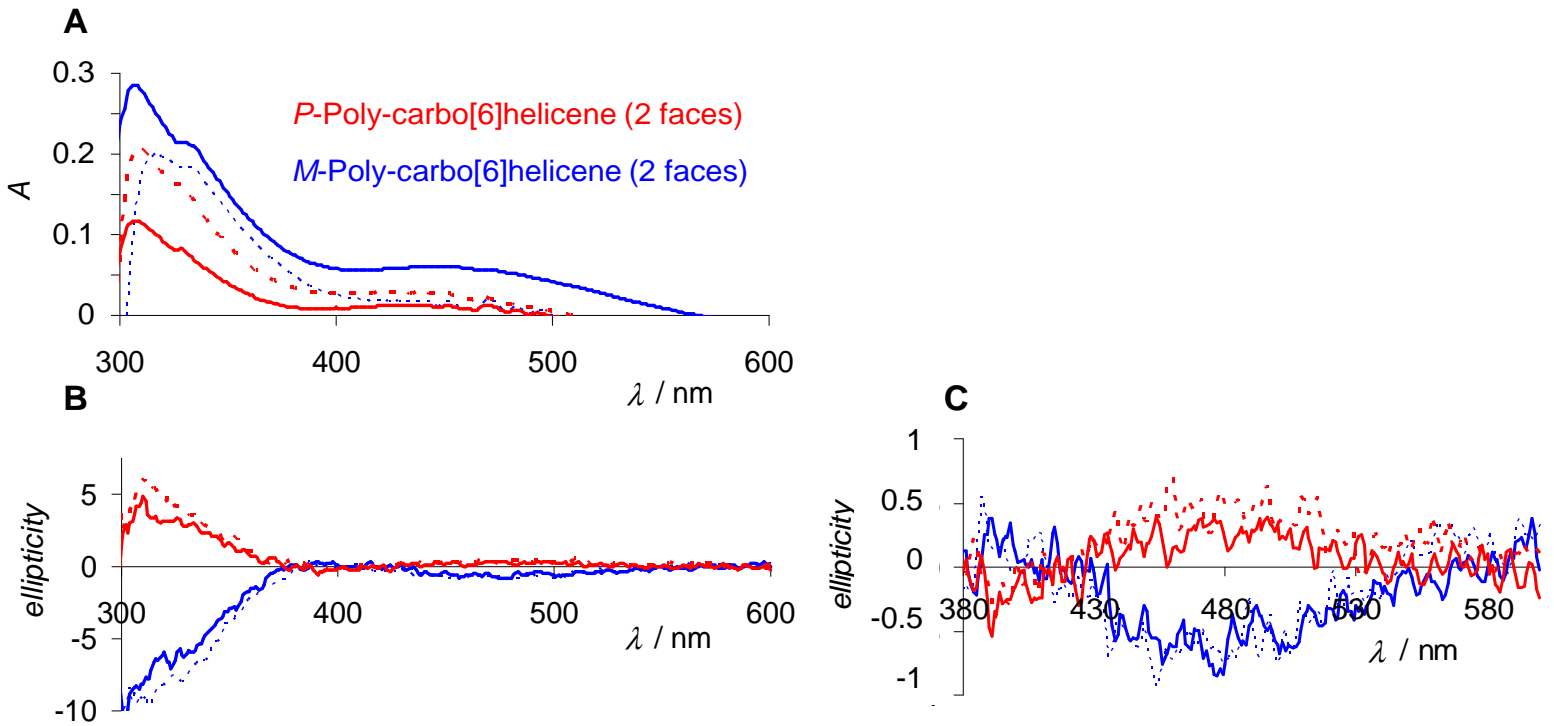
Fig. 7.

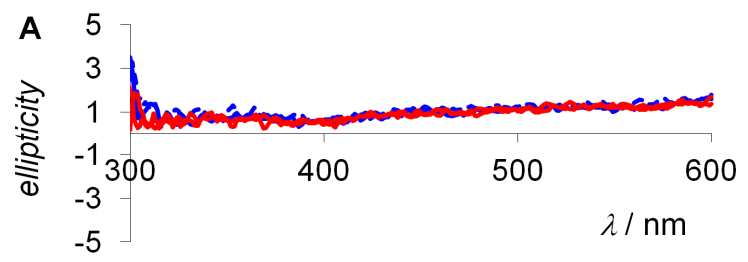

C

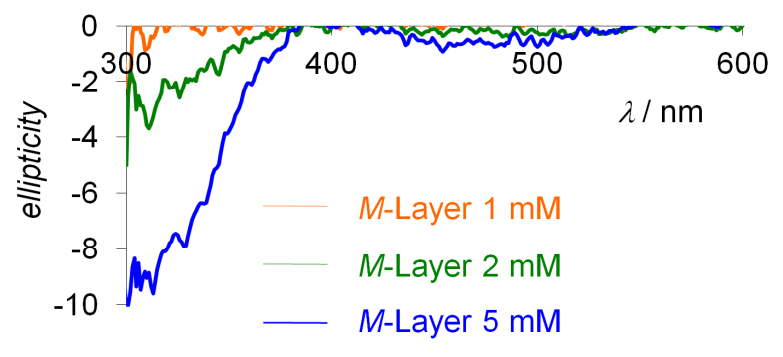


Fig. 8.
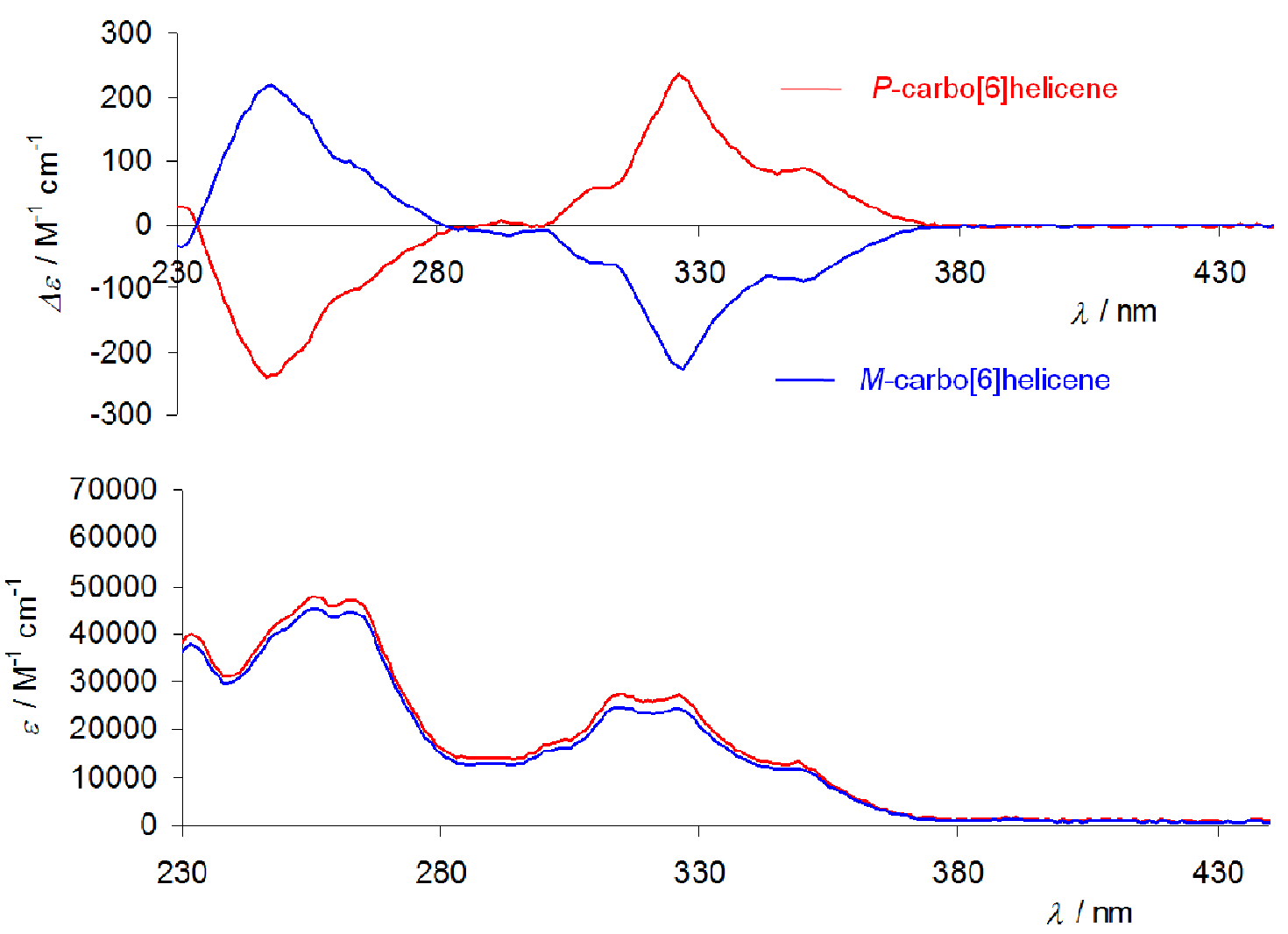